* Mestrando em Direito Negocial pela Universidade Estadual de Londrina - UEL (2019/2021). Bacharel em Direito pela UEL (2009), pós-graduado em Direito Aplicado pela Escola da Magistratura do Paraná (2011) e em Direito Civil e Empresarial pela Faculdade de Direito Prof. Damásio de Jesus (2015). Professor, servidor do Tribunal de Justiça do Estado do Paraná, mediador judicial e advogado. E-mail: danielmarinhocorrea@ gmail.com.

** Doutora em Direito das Relações Sociais, Área de Concentração em Direito Civil Comparado pela PUC-SP. Mestrado em Direito Negocial (2002) e Graduação em Direito (1989) pela Universidade Estadual de Londrina. Professora do Programa de Mestrado em Direito Negocial e do Curso de Graduação e Pós-graduação em Direito da Universidade Estadual de Londrina. Professora Colaboradora-Convidada do Curso de Pós-graduação em Direito Civil Contemporâneo do Instituto Brasileiro de Estudos e Pesquisas Socioeconômicas. Coordenadora da Revista Eletrônica de Direito Privado da UEL. Membro da Comissão Coordenadora Geral do Congresso de Direito da Universidade Estadual de Londrina. Vice Coordenadora do Programa de Mestrado em Direito Negocial- UEL. E-mail: anaclaudiazuin@live.com.

***Doutor e mestre em Direito Civil pela USP, Largo de São Francisco e possui mestrado em Direito Negocial pela Universidade Estadual de Londrina (1997). Atualmente, é professor adjunto da UniversidadeEstadualdeLondrina, onde leciona na graduação pós-graduação e Mestrado em Direito Negocial. É professor da Pontifícia Universidade Católica do Paraná, atuando na graduação e pós-graduação. Professor da Escola Superior da Advocacia do Paraná e da Escola do Ministério Público do Paraná. É coordenador do Curso de Especialização em Direito Civil pela Universidade Estadual de Londrina. E-mail: wagnermarquesi@uol.com.br.

\section{A Judicialização Das Questões Relativas À Recusa Do Estado Em Fornecer Medicamentos De Alto Custo}

\author{
The Judicialization Of Issues Relating To The State's \\ Refusal To Provide High-Cost Drugs
}

\section{Daniel Marinho Corrêa* Ana Cláudia Zuin Mattos do Amaral* Roberto Wagner Marquesi*}

Como citar: CORRÊA, Daniel Marinho; AMARAL, Ana Cláudia Zuin Mattos do; MARQUESI, Roberto Wagner. A judicialização das questões relativas à recusa do Estado em fornecer medicamentos de alto custo. Scientia Iuris, Londrina, v. 25, n. 1, p. 49-67, mar. 2021. DOI: $10.5433 / 2178-8189.2021 v 25 n 1 p 49$. ISSN: $2178-8189$.

Resumo: O presente artigo científico aborda os problemas legais oriundos da negativa do Poder Executivo de fornecer gratuitamente à população remédios de alto valor financeiro. Aborda os direitos fundamentais à vida e à saúde à luz do fundamento cardeal da dignidade da pessoa humana. Analisa as leis que disciplinam o acesso da população aos serviços públicos de saúde, examinando também as espécies normativas que tratam do fornecimento de medicamentos. Considera os meios judiciais de que dispõe a parte para exigir dos entes federativos fármacos de alto custo, assim como tece considerações sobre a interdependência entre as funções do Estado. Utilizou-se o método dedutivo para o exame da doutrina, por intermédio de pesquisa bibliográfica centrada em elegidos livros e periódicos que compreendam, sobretudo, ao campo do Direito Constitucional.

Palavras-chave: Direito constitucional. Direito à saúde. Fornecimento de medicamentos. Judicialização em caso de recusa.

Abstract: This scientific article addresses the legal problems arising from the Executive Branch's refusal to provide free medication of high financial value to the population. This paper examines the fundamental rights to life and health in the light of the cardinal foundation of human dignity. It also analyzes the laws that regulate the population's access to public health services, also examining the normative aspects that deal with the supply of medication. It considers the judicial means available 
to the party to demand high-cost drugs from federal entities, as well as making considerations about the interconnection of the many functions of the State. The deductive method was used to examine doctrines, by means of bibliographical research focused on selected books and scientific articles that comprise, above all, the field of Constitutional Law.

Keywords: Constitutional law. Right to health. Drug supply. Judicialization in case of refusal. 


\section{INTRODUÇÃO}

A Constituição Federal assegura a todos o direito à vida, à saúde e aos medicamentos, dispondo ser dever do Estado, por meio da função executiva, disponibilizar meios para o exercício desses direitos.

Valendo-se do método dedutivo, este artigo tem como escopo demostrar qual é o papel do Estado para dar concretude aos direitos fundamentais à vida e à saúde, no que tange ao fornecimento de medicamentos de elevado custo à população, bem como estabelecer os beneficiários de tais medicamentos.

Partir-se-á do pressuposto de que a saúde é direito assegurado constitucionalmente, e que é dever do Estado garanti-la por meio da implementação de políticas públicas capazes de atingir o fim almejado, ou seja, a qualidade da saúde da população, por meio do acesso aos medicamentos, inclusive os de alto custo financeiro.

Considera-se, ainda, que a saúde está atrelada a outros direitos assegurados pela Constituição Federal, como a vida, de modo que a infração a um desses direitos acarreta a negativa de todos os outros.

Realizada a opção pelo método dedutivo, analisa-se como o Poder Judiciário deve agir em caso de negativa de fornecimento de medicamentos por parte do Poder Executivo, bem como se essa conduta constitui ato lesivo aos direitos fundamentais do ser humano.

\section{O DIREITO À VIDA, À SAÚDE E AO MEDICAMENTO}

A Constituição Federal de 1988 declara ser a vida direito fundamental da pessoa humana. Tal direito, do qual se irradiam os direitos fundamentais, tem tamanha relevância, que é assegurado por vários preceitos constitucionais, de modo que, logo no artigo $1^{\circ}$ da $\mathrm{CF}$, o constituinte já revela sua preocupação para com a vida, instituindo, como um dos fundamentos do Estado, a dignidade da pessoa humana.

Por sua vez, o artigo $5^{\circ}$, caput, consagra a vida como direito fundamental, assegurando-o, ao mesmo tempo, na medida em que garante sua inviolabilidade: "todos são iguais perante a lei, sem distinção de qualquer natureza, garantindo-se aos brasileiros e aos estrangeiros residentes no País a inviolabilidade do direito à vida, à liberdade, à igualdade, à segurança e à propriedade”:

A vida é a intimidade conosco mesmo, saber-se e dar-se conta de si mesmo, um assistir a si mesmo e um tomar posição de si mesmo. Por isso é que ela constitui a fonte primária de todos os outros bens jurídicos. De nada adiantaria a constituição assegurar outros direitos fundamentais como a igualdade, a intimidade, a liberdade, o bem-estar, se não exigisse a vida humana nem desses direitos (SILVA, 2005, p. 198).

Dessa forma, pode-se detectar a preocupação legal de preservar e assegurar o direito à vida, vez que, sem sua garantia plena, a pessoa humana não tem condições de gozar dos demais direitos 
conferidos pela própria Constituição.

Do direito à vida decorre o direito à saúde, na medida em que esta é um dos elementos necessários para viver com dignidade, de modo que vida sem saúde resulta na negativa do princípio da dignidade.

A Constituição Federal confere a todos o direito à saúde, catalogando-o como direito social dentre os direitos fundamentais, cujo exercício se dá nos termos do art. $6^{\circ}$. Além disso, a Constituição dispõe ser dever do Estado garanti-lo mediante políticas sociais e econômicas que visem tanto à prevenção de doenças como o tratamento a quem dele necessite, conforme enunciado em seu art. 196.

Paralelamente, entendem Joaquim José Gomes Canotilho e Vital Moreira (1984, p. 342) que o direito à saúde admite dois aspectos, um de caráter negativo, "que consiste no direito a exigir do Estado (ou de terceiros) que se abstenha de qualquer acto que prejudique a saúde", outro de caráter positivo, que constitui o direito às "medidas e prestações estatais visando à prevenção das doenças e o tratamento delas".

Vê-se, pois, que o direito à saúde é efetivado por meio de um aparato público criado e mantido pelo Estado. Tal mecanismo se destina, dentre outras medidas, ao fornecimento de medicamentos.

Então, o Estado criou o Sistema Único de Saúde por intermédio da Lei 8.080, de 19 de setembro de 1990, para que o direito à saúde seja exercido de modo mais eficaz, sendo regido por princípios, dentre os quais destacam-se: (i) a integralidade da assistência, na medida em que deve ser oferecido integral tratamento necessário à cura, desde consultas médicas até intervenções cirúrgicas, incluindo assistência farmacêutica; (ii) universalidade de acesso aos serviços de saúde em todos os níveis de assistência, por força do qual todas as pessoas têm direito a valer-se dos serviços de saúde, sendo vedado qualquer obstáculo ao acesso; (iii) igualdade da assistência, em que todas as pessoas devem receber idêntico tratamento, objetivamente considerado, sem qualquer discriminação ou privilégio (BRASIL, 1990).

O direito ao medicamento enquadra-se no direito à saúde, porquanto deve ser efetivado tanto na prevenção quanto no tratamento de doenças; assim o medicamento está relacionado a medidas profiláticas, curativas, paliativas ou para diagnóstico.

Portanto, observa-se que o direito à vida, à saúde e ao medicamento estão interligados numa relação de interdependência, sendo dever do Poder Executivo implantar políticas públicas capazes de garantir sua efetivação.

O Executivo detém vários meios para garantir os direitos fundamentais aqui mencionados, especialmente em relação ao fornecimento de medicamentos. Nesse passo, várias leis e portarias foram editadas para descrever a competência de cada ente federativo para implementação do direito à vida, à saúde e aos medicamentos.

\section{O PAPEL DO PODER EXECUTIVO NO FORNECIMENTO DE MEDICAMENTOS DE ELEVADO CUSTO}

O papel do Estado no fornecimento de medicamentos de elevado custo consiste num dever 
instituído pela Constituição Federal ao preceituar, em seu artigo 196, que a saúde é direito de todos e dever do Estado. O Ministério da Saúde e as Secretarias Estaduais de Saúde determinam, por meio de portarias, quais os medicamentos que devem ser fornecidos pelo Estado.

Entretanto, a obrigação do Estado em fornecer medicamentos à população vai além dessas normas administrativas, pois não é possível restringir o exercício de um direito constitucional. A Constituição Federal estabelece que a saúde é direito de todos e dever do Estado, englobando a assistência farmacêutica. Assim, é dever do Poder Executivo assegurar o acesso ao medicamento, especificamente os de elevado custo, a quem dele necessita.

Além disso, vários preceitos constitucionais estão relacionados com o direito à saúde, como o princípio da dignidade da pessoa humana e a promoção do bem-estar de todos. A respeito do princípio da dignidade da pessoa humana, afirma Cármen Lúcia Antunes Rocha (1999, p. 33-34):

A expressão daquele princípio como fundamento do Estado do Brasil quer significar, pois, que esse existe para o homem, para assegurar condições políticas, sociais, econômicas e jurídicas que permitam que ele atinja os seus fins; que o seu fim é o homem, como fim em si mesmo que é, quer dizer, como sujeito de dignidade, de razão digna e supremamente posta acima de todos os bens e coisas, inclusive do próprio Estado. Esse princípio vincula e obriga todas as ações e políticas públicas, pois o Estado é tido como meio fundado no fim que é o homem, ao qual de há de respeitar em sua dignidade fundante do sistema constituído (constitucionalizado). É esse acatamento pleno ao princípio que torna legítimas as condutas estatais, as suas ações e as suas opções.

Portanto, considerando que uma pessoa doente apenas consegue viver, com dignidade, se ela tiver acesso aos fármacos necessários ao seu tratamento clínico, decorre que, por ser fundamento do Estado a dignidade da pessoa humana, o poder público tem o dever de fornecer medicamentos de elevado custo aos que dele necessitam.

Ademais, a referida autora observa que "o respeito à dignidade da pessoa humana obriga irrestrita e incontornavelmente o Estado, seus dirigentes e todos os atores da cena política governamental, pelo que tudo que o contrarie é juridicamente nulo" (ROCHA, 1999, p. 36).

Dessa forma, o Poder Executivo não pode se abster de garantir o acesso ao medicamento excepcional, pois agindo desta maneira estará desrespeitando o princípio da dignidade da pessoa humana.

$\mathrm{O}$ art. $3^{\circ}$, inciso IV, da Constituição Federal insere como objetivo do Estado a promoção do bem de todos. Esta é mais uma razão para afirmar que é obrigação do Estado o fornecimento de medicamentos, especialmente os de elevado custo, para assegurar o bem-estar daqueles que precisam de tratamento clínico. $\mathrm{O}$ artigo $5^{\circ}$, também da Constituição Federal, inicia o título referente aos direitos fundamentais enunciando que a inviolabilidade do direito à vida é garantia inerente a todos.

Para garantir esse direito é necessário que o Poder Executivo assegure também o direito à saúde, também direito fundamental, estando previsto no artigo $6^{\circ}$ da CF. Este direito engloba o 
direito aos medicamentos de elevado custo, na medida em que, para assegurar o direito à saúde, o Poder Executivo tem que fornecer medicamentos a quem dele necessitar.

Dessa forma, observa-se que o direito à vida, à saúde e ao medicamento estão atrelados, sendo que todos eles devem ser assegurados pelo Poder Executivo. É esse o do Supremo Tribunal Federal, esposado no voto do Ministro Celso de Mello (Agravo no Recurso Extraordinário ${ }^{\circ}$ 273.834-4):

O direito à saúde representa conseqüência constitucional indissociável do direito à vida. $\mathrm{O}$ direito público subjetivo à saúde representa prerrogativa jurídica indisponível assegurada à generalidade das pessoas pela própria Constituição da República (art. 196). Traduz bem jurídico constitucionalmente tutelado, por cuja integralidade deve velar, de maneira responsável, o Poder Público, a quem incumbe formular - e implementar - políticas sociais e econômicas idôneas que visem a garantir, aos cidadãos, inclusive àqueles portadores dos vírus HIV, o acesso universal e igualitário à assistência farmacêutica e médico-hospitalar. $\mathrm{O}$ direito à saúde - além de qualificar-se como direito fundamental que assiste a todas as pessoas - representa conseqüência constitucional indissociável do direito à vida. O Poder Público, qualquer que seja a esfera de atuação no plano da organização federativa brasileira, não pode mostrar-se indiferente ao problema da saúde da população, sob pena de incidir, ainda que por censurável omissão, em grave comportamento inconstitucional (BRASIL, 2001).

Deste modo, se o doente precisa de medicamento de elevado custo, o Poder Executivo tem o dever de fornecê-lo, pois negar tal medicamento seria mitigar o direito constitucional à vida e à saúde dos quais ele é titular.

Reforçando esse entendimento, o artigo 196 da Constituição Federal, expressamente, dispõe que é dever do Estado assegurar o direito à saúde e também estabelece que aquele deve implementar políticas públicas capazes de assegurar tal direito, desenvolvendo projetos de distribuição de medicamentos excepcionais além de outras medidas voltadas à área da saúde.

Para atender aos preceitos de tal dispositivo constitucional, o Estado criou a Política Nacional de Medicamentos e o Programa de Medicamentos de Dispensação Excepcional, conforme mencionado.

A execução do Programa de Medicamentos de Dispensação Excepcional é de responsabilidade dos Estados federados, porém, não se exclui a responsabilidade dos demais entes públicos na implementação desse programa. Então, cada Estado membro tem competência para elaboração da lista dos medicamentos a serem distribuídos.

Entretanto, como essa listagem não engloba todos os medicamentos necessários ao tratamento de todas as doenças existentes, não pode servir como limitador do dever estatal de fornecimento, não configurando justificativa a ausência de algum medicamento na lista para ser negado.

Decisões do Supremo Tribunal Federal indicam, ainda, que os medicamentos pretendidos, embora não constem na lista de medicamentos relativos ao Programa de Medicamentos de Dispensação Excepcional, subsiste o dever do Poder Executivo em fornecê-los, tendo em vista 
que este não indicou outro fármaco capaz de produzir o mesmo efeito do medicamento pretendido. É o que entende a Ministra Ellen Gracie ao julgar o pedido de Suspensão de Segurança no 3382, impetrado pelo Estado do Rio Grande do Norte:

Finalmente, como bem asseverou a Procuradoria-Geral da República, "apesar de alegar que o fornecimento do medicamento pleiteado não está previsto no Programa de Dispensação de Medicamentos em caráter excepcional, o Estado requerente não demonstra a eficácia de outras drogas, tampouco comprova que estão sendo disponibilizadas para o doente, de forma que prevalece a premissa de imprescindibilidade do fármaco pleiteado para a manutenção da saúde e preservação da vida do autor" (fl. 85). 7. Assim, no presente caso, atendo-me à insuficiência econômica dos pais do impetrante para custear a aquisição do medicamento em apreço, à enfermidade em questão, à urgência na utilização do medicamento Revatio (citrato de sildenafil), devidamente registrado junto à Anvisa, entendo que, em face dos pressupostos contidos no art. $4^{\circ}$ da Lei $4.348 / 64$, a ausência do medicamento solicitado poderá ocasionar graves e irreparáveis danos à saúde e à vida do paciente, ocorrendo, pois, o denominado perigo de dano inverso, o que demonstra, em princípio, a plausibilidade jurídica da pretensão deduzida na ação mandamental, cuja liminar foi devidamente mantida, à unanimidade, pelo Plenário do Tribunal de Justiça do Estado do Rio Grande do Norte no julgamento de seu mérito, realizado em 07.11.2007. 8. Ante o exposto, indefiro o pedido (BRASIL, 2007).

No mesmo sentido é o entendimento da Suprema Corte, posto no voto do Ministro Joaquim Barbosa, no julgamento do Agravo de Instrumento $n^{\circ}$ 507072, interposto pelo Estado de Minas Gerais:

Ademais, consolidou-se a jurisprudência desta Corte no sentido de que o Estado não pode furtar-se do dever de propiciar os meios necessários ao gozo do direito à saúde por todos os cidadãos. Se uma pessoa necessita, para garantir o seu direito à vida, de medicamento que não esteja na lista daqueles oferecidos gratuitamente pelas farmácias públicas, é dever solidário da União, do estado e do município fornecê-lo. Nesse sentido, AI 396.973 (rel. min. Celso de Mello, DJ 30.04.2003), RE 297.276 (rel. min. Cezar Peluso, DJ 17.11.2004) e AI 468.961 (rel. min. Celso de Mello, DJ 05.05.2004). O acórdão não divergiu desse entendimento. Do exposto, nego seguimento ao agravo de instrumento (BRASIL, 2006).

Assim, verifica-se que o dever do Estado, por meio do Poder Executivo, ao fornecimento de medicamentos de elevado custo é amplo, sendo dele a obrigação de fornecer os fármacos necessários ao tratamento a quem deles necessita.

Em que pese tal obrigação, o Poder Executivo busca meios para tentar se eximir do dever do fornecimento de tais medicamentos, argumentando no sentido de existir dificuldade financeira e orçamentária para adimplemento da aludida obrigação.

Não se pode olvidar da decisão proferida por Carlos Alberto Violante (2002, p. 75), ao apreciar o pedido de assistência farmacêutica formulado em uma ação ordinária contra a Fazenda 
do Estado de São Paulo:

[...] é cristalino o dever do Estado de prestar atendimento ao doente, e não o atendimento precário, inadequado e incompleto, que, lamentavelmente, defende a Fazenda-ré. Pretende não atender as justas reivindicações do autor, sob o pequeno e mesquinho argumento de que estaria abrindo perigoso precedente, com grave risco às finanças públicas e que, então, o autor seria um privilegiado em detrimento de toda a coletividade. Se precedente houvesse, seria um salutar precedente, pois atender à saúde de todos não é negar atendimento adequado a cada um dos cidadãos necessitados. Não se compreende bem, mas consegue a Fazenda Pública Estadual concluir que o atendimento às necessidades do autor, reconhecidamente enfermo e carente, seja contrário ao interesse público. Bem maior que a vida humana não há. Prestar atendimento à saúde do autor é protegerlhe a vida, com indubitável apoio no interesse público da coletividade, superior a qualquer dificuldade de ordem financeira e orçamentária, aliás solucionável. [...] É muito simplista a posição da ré, de eximir-se de prestar o adequado tratamento à saúde do autor, para ele questão de vida ou morte, para a Fazenda a preocupação com o orçamento.

Corrobora esse entendimento André Ramos Tavares (2007, p. 755), aduzindo que "não só todos têm direito à saúde como esta deve ser prestada de maneira completa, sem exclusões de doenças e patologias, por dificuldades técnicas ou financeiras do Poder Público”.

Dessa forma, pode-se observar que o bem jurídico protegido pelo direito à saúde, e consequentemente, ao medicamento, é a vida, e sendo esse um bem supremo, questões financeiras e orçamentárias não podem se sobrepor a ele, de modo que o Poder Executivo não pode se furtar da obrigação de fornecer medicamentos de elevado custo considerando apenas tais elementos de ordem financeira.

Assim, o dever do Poder Executivo ao fornecimento de medicamentos de elevado custo deve ser maior que sua preocupação com as finanças públicas e com o respectivo orçamento, na medida em que, para esses dois elementos, existem soluções que podem ser encontradas pelos administradores, a passo que, para um doente, o tratamento imediato é indispensável à manutenção da vida.

Outra questão relevante a respeito da obrigação do Estado no fornecimento de medicamentos, leia-se os de elevado custo, refere-se à aplicabilidade das normas constitucionais relativas a esse assunto.

Embora exista a Lei n. 8.080/90, a qual dispõe sobre questões relativas às ações e serviços de saúde, as normas constitucionais referentes a direitos fundamentais têm aplicação imediata, conforme estabelece o artigo $5^{\circ}, \S 1^{\circ}$, da Constituição Federal (BRASIL, 1988).

Rodrigo Lacerda Carelli (2003, p. 256) entende que os direitos fundamentais não carecem da legislação inferior para se auto-realizarem, devendo ser garantidas de imediato pelo Estado, "instância de concretização, mas também instância de decisão para a realização dos direitos do Homem", com vistas à sua concretização. Nesse sentido, cumpre ainda trazer o entendimento de 
Márcia Corrêa (1998, p. 80):

A aplicabilidade direta, a nosso ver, estende-se à totalidade dos direitos fundamentais e não apenas ao Capítulo I, do Título II, da Constituição. Isto porque o legislador constituinte optou por utilizar, no art. $5^{\circ}, \S 1^{\circ}$, a abrangente expressão direitos e garantias fundamentais. Ora, se pretendesse o constituinte restringir a aplicabilidade direta somente aos direitos individuais e coletivos, teria certamente empregado tal expressão, que constitui, aliás, epígrafe do capítulo I, ou então diria, por exemplo, que as normas definidoras dos direitos estabelecidos neste capítulo têm aplicação imediata.

Considerando que o direito ao medicamento decorre diretamente do direito à vida e à saúde, ambos direitos fundamentais, sendo dotados, portanto, de aplicabilidade imediata, verifica-se mais uma razão para que o Poder Executivo forneça medicamentos de elevado custo a quem deles necessita.

Portanto, tendo em vista todos os argumentos levantados, verifica-se que é obrigação do Estado, compreendendo a União, os Estados Federados, o Distrito Federal e os Municípios, por meio dos respectivos Poderes Executivos, o fornecimento de medicamentos de elevado custo.

\section{A TEORIA DA RESERVA DO POSSÍVEL}

Em que pese tal dever, vale-se o Estado da teoria da reserva do possível, a qual visa demonstrar que o ente estatal deve garantir apenas o mínimo do direito à saúde. Desse modo, a concretização do direito à saúde depende, segundo José Joaquim Gomes Canotilho (2008, p. 481), de grandes disponibilidades financeiras por parte do Estado, de modo que se adere à construção da dogmática da reserva do possível para afirmar que a existência dos direitos sociais pressupõe a existência de numerário nos cofres públicos.

Assim, a teoria da reserva do possível vem sendo muito utilizada em razão da escassez de recursos públicos para financiar os meios de assegurar os direitos fundamentais instituídos pela Constituição Federal de 1988:

A teoria da reserva do possível entende que os direitos sociais não são ilimitados, já que encontram limites na possibilidade orçamentária do Estado, ou seja, os direitos sociais só serão efetivados quando o poder público estiver possibilitado financeiramente (DALVI, 2008, p. 273).

Neste panorama, o direito à saúde, e consequentemente ao medicamento, é direito social, de forma que está submetido, em tese, à teoria da reserva do possível. Ademais, para José Joaquim Gomes Canotilho (2008, p. 481), a vinculação razoável e possível do Poder Executivo em relação aos direitos sociais consiste na garantia do mínimo existencial, por meio do qual estaria cumprindo o dever estatal de garantir a dignidade da pessoa humana.

Entretanto, ao analisar essa questão, observa-se que o direito à saúde e ao medicamento é 
também direito fundamental, haja vista que está intimamente relacionado com o direito à vida e com o princípio da dignidade a pessoa humana.

Assim, tais direitos devem ser prioridade do Estado, de modo que é inadmissível garantir apenas o mínimo quando ele deve usar de todos os meios para assegurá-lo de forma plena, vez que o uso do medicamento proporciona vida mais digna, concretizando o princípio da dignidade da pessoa humana, consagrado pela Constituição Federal como fundamento do Estado, bem como concretiza a meta constitucional idealizada pelo Estado em promover o bem-estar de todos.

A tarefa estatal - que não pode ser transferida para o setor privado, pois assim os menos favorecidos restariam de vez desamparados - é realmente complexa, uma vez que exige muitos investimentos. A CF criou uma série de fontes de arrecadação na área da saúde, e de fato são realizados investimentos vultosos, que, no entanto, estão longe de ser suficientes. Ao lado da massiva arrecadação, vive a Administração Pública sob o manto da ineficiência e da falta de programas de Estado, sem falar na corrupção, mal que aos poucos vai digerindo as estruturas do Estado. Além disso, outros elementos concretos propiciam o aumento dos gastos, como o desenvolvimento das técnicas e aparelhos (sempre de alto custo), o crescimento de epidemias e o aumento da expectativa de vida da população (BARROSO, 2009, p. 49-50).

Dessa forma, observa-se que a garantia do direito à saúde é atividade que gera elevados custos ao Poder Executivo, devendo os gastos nesta área ser realizados de modo racional, o que não significa limitação de investimentos, de modo que esses devem ser centrados nas atividades essenciais, ou seja, assegurando direitos fundamentais.

Assim, a concretização desses direitos não deve ficar condicionada às possibilidades orçamentárias do Poder Executivo, de modo a não mitigar o direito à saúde e aos medicamentos essenciais às pessoas.

É evidente que a ausência total de recurso gera impossibilidade de implementar o direito à saúde, entretanto, os recursos existentes devem ser utilizados de modo a priorizar as ações nessa área. As questões orçamentárias devem ser resolvidas, dentro da legalidade, observando que os recursos públicos devem ser aplicados, prioritariamente, nas atividades essenciais, como o fornecimento de medicamentos.

Deste modo, ainda que não seja o ideal, o Poder Executivo deve garantir a máxima efetividade possível do direito à saúde, e não apenas reservar o mínimo de recursos a este setor fundamental ao exercício dos demais direitos constitucionais.

Segue daí que a reserva do possível é uma teoria incongruente com o Texto Constitucional. Tendo este trabalho discorrido sobre o dever do Estado de fornecer medicamentos de elevado custo, bem como a respeito da teoria da reserva do possível, é mister agora ressaltar quem são os beneficiários do medicamento gratuito.

\section{OS DESTINATÁRIOS DOS MEDICAMENTOS DE ALTO CUSTO}

No tocante à distribuição de medicamentos de elevado custo, o Poder Executivo não pode criar obstáculos de acesso aos fármacos indispensáveis à manutenção de vida digna valendo-se de 
mecanismos de segregação.

Assim, a Lei 8.080/1990, que regula as ações e serviços de saúde, consagra o princípio da universalidade em seu artigo $2^{\circ}, \S 1^{\circ}$, dispondo que:

Art. $2^{\circ}$ A saúde é um direito fundamental do ser humano, devendo o Estado prover as condições indispensáveis ao seu pleno exercício. $\S 1^{\circ} \mathrm{O}$ dever do Estado de garantir a saúde consiste na formulação e execução de políticas econômicas e sociais que visem à redução de riscos de doenças e de outros agravos e no estabelecimento de condições que assegurem acesso universal e igualitário às ações e aos serviços para a sua promoção, proteção e recuperação (BRASIL, 1990).

Como foi visto, à luz do princípio da universalidade, todos têm direito de receber tratamento igualitário do Estado, independentemente de suas características socioeconômicas. Nesse sentido, Luiz Alberto David Araújo e Nunes Junior (2007, p. 487) entende que "o princípio do acesso universal traduz que os recursos e ações na área de saúde pública devem ser destinados ao ser humano enquanto gênero, não podendo, portanto, ficar restritos a um grupo, categoria ou classe de pessoas".

Assim, o Poder Executivo não pode considerar renda per capita ou familiar para conceder ou negar auxílio farmacêutico a quem dele necessita, pois tal conduta consiste em uma forma de discriminação, repudiada pela Constituição Federal.

Um ser humano que aufere renda superior à média nacional, considerado de classe social alta, pode não suportar o ônus gerado pelo custeio de um tratamento através de medicamento de elevado custo, seja pelo seu alto valor pecuniário unitário ou pelo uso contínuo ou prolongado.

A distribuição de medicamentos deve ser igualitária e universal, pois o Poder Executivo não pode privilegiar determinada classe social em detrimento de outra. Apesar de as pessoas de baixa renda precisarem de maior atenção do Estado, este não deve prestar auxílio farmacêutico apenas aos mais carentes e deixar de observar as necessidades dos que detêm maior poder aquisitivo.

O tratamento igualitário ao qual todos têm direito refere-se à forma de atendimento, de modo que duas pessoas distintas, que sofrem da mesma doença, devem ser atendidas da mesma maneira, para não privilegiar uma e nem negligenciar outra.

Para efeito de fornecimento de medicamentos, o fato de a pessoa que solicita o medicamento ser ou não usuária do Sistema Único de Saúde não deve ser considerado, na medida em que, conforme exposto anteriormente, pelos princípios constitucionais da dignidade da pessoa humana, da igualdade e da universalidade, ao Poder Executivo não é dado usar critérios discriminatórios para distribuição de medicamentos.

Uma pessoa que detém condições de suportar o custo de um tratamento clínico particular ou por meio de plano de saúde, pode não conseguir adquirir o medicamento necessário ao seu tratamento, haja vista que o alto custo pode se dar em razão de seu valor unitário, assim como pode decorrer do seu uso contínuo ou prolongado.

O fato de a pessoa não ter necessitado da assistência do Poder Executivo durante seu 
tratamento clínico não significa que, posteriormente, ela não possa ter direito a auxilio farmacêutico proveniente do Estado. Ao negar o fornecimento de um medicamento a uma pessoa nessa situação, o Estado nega, também, o exercício do direito fundamental à saúde

Portanto, qualquer pessoa que necessite de um auxilio farmacêutico por parte do Estado, tem direito de recebê-lo independente de sua condição socioeconômica e de ser ou não usuário do Sistema Único de Saúde.

\section{O PAPEL JUdiciário diANTE DA NEGATIVA do PODER EXECUTIVO NO FORNECIMENTO DE MEDICAMENTOS DE ELEVADO CUSTO}

Conforme analisado, o Estado tem o dever de fornecer medicamentos de elevado custo à população, mas, mesmo assim, busca meios para se eximir dessa obrigação. Pode ocorrer de o Poder Executivo, nas vias administrativas, negar-se a fornecer o medicamento de elevado custo.

Tendo em vista que o fornecimento de fármacos, ainda que de alto custo, é englobado pelo direito à saúde, sendo esse direito de todos e dever do Poder Executivo, a negativa do seu fornecimento lesiona direitos fundamentais atribuídos a todos pela Constituição.

A Constituição Federal assegura, em seu artigo $5^{\circ}$, inciso XXXV, que não será afastada do Judiciário qualquer lesão ou ameaça a direitos. Trata-se de garantia do livre acesso à justiça, complementada pelos princípios do devido processo legal. Deste modo, o Judiciário tem condições de atuar, quando provocado, frente à negativa do Poder Executivo de fornecimento de medicamentos à população, de modo a assegurar que o direito individual, a vida, seja respeitado.

É de verificar-se Paulo Fernando Silveira (2007, p. 151), quando aduz que sem o livre acesso ao Poder Judiciário, o qual tem a missão de resguardar o direito e os interesses da minoria, "não é possível alguém conseguir defender seus direitos individuais". Trata-se, portanto, do exercício do direito de buscar a tutela do Judiciário, utilizando-se dos instrumentos cabíveis, quando existir alguma lesão ou ameaça a direito.

O Estado possui poder político, composto de três funções: a executiva, a legislativa e a jurisdicional. José Afonso da Silva (2005, p. 106) revela que o exercício de tais funções é indispensável, na medida em que visa ordenar as relações entre os indivíduos da sociedade estatal, para manter um mínimo de ordem e estimular ao máximo o progresso, de modo a objetivar o bem comum.

AConstituição Federal estabelece, em seu artigo 2º que "são Poderes da União, independentes e harmônicos entre si, o Legislativo, o Executivo e o Judiciário" (BRASIL, 1988). Dessa forma, o diploma constitucional confia cada uma das funções estatais a órgãos diferentes, a saber: órgão ou poder Executivo, órgão ou poder Legislativo e órgão ou poder Judiciário, que exercem as respectivas funções.

Assim, esta divisão de poderes não é prejudicada quando o Judiciário, por meio de uma decisão judicial, impõe obrigações ao Executivo com o intuito de preservar direitos fundamentais, na medida em que apenas se utiliza do mecanismo de freios e contrapesos para defender tais direitos. Não se pode perder de vista o entendimento de Luís Roberto Barroso (2009, p. 50): 
[...] constitucionalismo traduz-se em respeito aos direitos fundamentais. E democracia, em soberania popular e governo da maioria. Mas pode acontecer de a maioria política vulnerar direitos fundamentais. Quando isso ocorre, cabe ao Judiciário agir. É nesse ambiente, é nessa dualidade presente no Estado constitucional democrático que se coloca a questão essencial: podem juízes e tribunais interferir com as deliberações dos órgãos que representam as maiorias políticas - isto é, o Legislativo e o Executivo -, impondo ou invalidando ações administrativas e políticas públicas? A resposta será afirmativa sempre que o Judiciário estiver atuando, inequivocamente, para preservar um direito um direito fundamental previsto na constituição ou para dar cumprimento à alguma lei existente.

Como se viu, além de dividir os poderes políticos, a Constituição Federal dispõe que eles devem ser harmônicos entre si. Tal harmonia é observada nas normas de cortesia de trato recíproco e no respeito às prerrogativas e faculdades inerentes a cada um, sobre isso, ressalta Pedro Abramovay (2012, p. 32) que:

A relação entre os Poderes não pode ser vista como fruto de atribuições expressas, predefinidas e impermeáveis. A única maneira de o princípio da separação de Poderes conviver com a democracia e exercer a sua principal função de combater o arbítrio é de um permanente ambiente de diálogo constitucional.

Vê-se, pois, que a divisão dos poderes políticos não é afetada quando o Poder Judiciário determina o fornecimento de medicamentos de elevado custo à população, vez que não se trata de usurpação da função do Poder Executivo, mas forma de controle e fiscalização exercida sobre os atos desse poder que afrontam direitos fundamentais inerentes à população: o direito à vida, saúde e, consequentemente, ao medicamento.

Outra discussão relevante consiste na vedação de o Judiciário poder determinar que o Poder Executivo forneça medicamentos de elevado custo à população, porque o Executivo e o Legislativo são compostos por pessoas eleitas pelo povo por meio da maioria de votos, sendo, portanto, seus representantes, manifestando, assim, a vontade de maioria, ao contrário do Judiciário, que não é poder formado por representantes da população.

Assim, dois dos três poderes governamentais instituídos são representativos, ou seja, representam a vontade da maioria pelo fato de seus componentes terem sido eleitos pela maioria. Entretanto, o direito da minoria não pode ser violado. Para tal direito ser salvaguardado, a Constituição Federal institui o Judiciário como um poder antimajoritário, justifica Paulo Fernando Silveira (2007, p. 137):

Para que o judiciário possa livremente e com segurança, exercer o controle da vontade da maioria, geralmente veiculada por lei, ele foi elevado à condição de pode político, com essa missão precípua: a de confrontar a vontade do legislador (hipoteticamente representando a vontade da maioria), com a Constituição, ou 
seja, a vontade geral da nação, ou do povo, de onde emana o todo o poder político dos três ramos governamentais.

Não se pode olvidar da divisão dos poderes trazida por Charles-Louis de Secondat Montesquieu (2000, p. 167-168): "existem em cada Estado três tipos de poder: o poder legislativo, o poder executivo das coisas que dependem dos direitos das gentes e poder executivo daqueles que dependem do direito civil". Esse terceiro poder ele chamou também de "poder de julgar", sustentando que "se os tribunais não devem ser fixos, os julgamentos devem sê-lo a tal ponto que nunca sejam mais do que um texto preciso da lei” (MONTESQUIEU, 2000, p. 168).

Portanto, o Judiciário atua no sentido de evitar que a legislação crie obstáculos à efetivação dos direitos individuais - sendo o maior desses o direito à vida - em razão deles não resplandecerem, na grande parte das vezes a vontade da maioria.

$\mathrm{O}$ direito à vida se desdobra em outros, sendo que um desses desdobramentos é o direito à saúde, o qual pode ser exigido do Poder Executivo, inclusive no que tange ao direito de receber dele medicamentos de elevado custo. Tal exigência pode ser feita através das vias judiciais, na medida em que há uma afronta ao direito individual à vida e à saúde quando o Poder Executivo nega o fornecimento de um desses medicamentos à população:

A nossa Constituição instituiu o judiciário como poder político não eleito, porém em igualdade de força política com os outros dois ramos governamentais. Ao judiciário, foi reconhecido o poder político de anular as leis feitas pelo Congresso Nacional e dos atos da administração pública que violarem a constituição (SILVEIRA, 2007, p. 138).

A omissão do Executivo de fornecer medicamentos configura um ato administrativo, ou seja, realizado pela administração pública, o qual é contrário à Constituição Federal, por infringir um direito fundamental. Assim, o Judiciário tem legitimidade para revertê-lo ao determinar que o medicamento pleiteado seja fornecido.

Ao ponderar questões referentes à negativa no fornecimento de medicamentos de elevado custo à população, os juízes estão desempenhando sua função de guardião do ordenamento jurídico brasileiro, atuando no sentido de evitar que direitos da população, em especial os direitos fundamentais, sejam violados, bem como a função de controle e fiscalização dos atos praticados pelos poderes Executivo e Legislativo.

Para o órgão forense observar essas questões relativas a medicamentos, é necessária a propositura de ações judiciais a fim de obter a tutela pretendida, vez que ele não age de ofício, ao contrário do Poder Executivo, o qual atua independente de provocação.

Os instrumentos hábeis para se buscar judicialmente que o Executivo cumpra sua obrigação de fornecer medicamentos de elevado custo à população consistem nas ações de conhecimento, no mandado de segurança e na ação civil pública, pois não existem ações específicas para a tutela do direito ao medicamento (GOUVÊA, 2003, p. 103). 
A escolha da ação judicial deve ser pautada nas características de cada uma delas, de modo a se optar pelo instrumento apto a atingir o fim desejado. No plano individual, o doente ou seu representante legal pode ingressar com ação de conhecimento ou mandado de segurança, enquanto em âmbito coletivo, o instrumento cabível é a ação civil pública.

A ação de conhecimento tramita sob o rito do procedimento ordinário. Esta possui uma fase específica para a produção de provas a qual se destina à realização de perícias e oitivas das partes e das testemunhas (THEODORO JUNIOR, 2007, p. 377). Assim, quem pleiteia o fornecimento de medicamentos de elevado custo por parte do Poder Executivo, que não tenha pré-constituídas as provas da eficácia do medicamento no seu tratamento clínico, deve utilizar esta ação, vez que, por meio de perícias, existe a possibilidade de comprovar a necessidade.

Por outro lado, possível também é o mandado de segurança. Conforme Hely Lopes Meirelles (2006, p. 21-22) trata-se de meio constitucional disponibilizado a toda pessoa física ou jurídica, órgão com capacidade processual ou universalidade reconhecida por lei, para a proteção de direito individual ou coletivo, líquido e certo, não amparado por habeas corpus ou habeas data, lesado ou ameaçado de lesão por ato de autoridade.

Idem com relação a Cassio Scarpinella Bueno (2010, p. 20), para quem “o mandado de segurança nasceu e se desenvolveu no direito brasileiro como medida apta para tutelar direitos lesionados ou ameaçados por autoridade publica".

Por sua vez, para Hely Lopes Meirelles (2006, p. 38) justamente pelo fato de proteger direitos líquidos e certos, ou seja, previamente comprovados, não há instrução probatória no mandado de segurança, sendo que as provas para demonstrar a liquidez e a certeza do direito devem acompanhar a inicial, salvo quando estas estiverem na posse da autoridade coatora. Assim, exige-se a prova pré-constituída das situações e fatos que embasam o direito invocado pelo impetrante.

No que tange aos medicamentos, a certeza e a liquidez exigidas para impetrar o mandado de segurança consistem na comprovação da eficácia do fármaco pleiteado, ou seja, na demonstração de que o medicamento requerido é o indicado para o tratamento das mazelas do impetrante. $\mathrm{O}$ direito lesado ou ameaçado por ato de autoridade é o direito à vida e à saúde. Tal ato consiste em omissão do Executivo, pelo fato dele ter negado o fornecimento do medicamento.

A ação civil pública, de sua parte, foi instituída pela Lei 7.347/85 para tutelar interesses difusos e coletivos da sociedade, sendo que o seu artigo $1^{\circ}$ arrola, exemplificativamente, situações em que é cabível a propositura desta ação. Têm legitimidade ativa o Ministério Público, as pessoas jurídicas estatais, autárquicas e paraestatais.

É de ser revelado que, para Márcio Flávio Mafra Leal (1998, p. 188) a ação civil pública “era originalmente o nome da ação do Ministério Público como autor, não havendo relação com a dimensão difusa e coletiva do direito material, dimensão esta assumida somente com a Lei $7.347 / 85 \%$.

Por sua vez, Hely Lopes Meirelles (2006, p. 179-180) entende que o Ministério Público, primeiro legitimado da ação, detém melhores condições para proposição da ação, "por sua independência institucional e atribuições funcionais. Além disso, está isento de custas e honorários 
no caso de improcedência da demanda".

Ademais, a própria CF, em seu artigo 127, atribui ao Ministério Público a defesa da ordem jurídica, do regime democrático e dos interesses sociais e individuais indisponíveis. Assim, o Ministério Público tem legitimidade para propor ação civil pública no âmbito do direito à saúde, especificamente no que tange a medicamentos, uma vez que se trata de interesses social e coletivo, sendo, ainda, tal direito indisponível.

O Ministério Público pode propor ação civil pública visando à inclusão de determinados medicamentos de elevado custo da Relação Nacional de Medicamentos, bem como nas relações de medicamentos elaboradas pelas Secretarias Estaduais de Saúde, para que o fármaco seja distribuído gratuitamente à população, através do Programa de Medicamentos de Dispensação Excepcional.

Nesse sentido, Luís Roberto Barroso (2009, p. 35-36):

O Judiciário poderá vir a rever a lista elaborada por determinado ente federativo para, verificando grave desvio na avaliação dos Poderes Públicos, determinar a inclusão de determinado medicamento. O que se propõe, entretanto, é que essa revisão seja feita apelas no âmbito das ações coletivas (para a defesa de direitos difusos ou coletivos e cuja decisão produz efeitos erga omnes no limite territorial da jurisdição de seu prolator).

Assim, esse entendimento reforça a afirmação de que as listagens de medicamentos elaboradas pelos Estados membros podem ser revisadas por meio de uma ação civil pública, a qual é uma ação coletiva que tutela direitos indisponíveis, difusos e coletivos. Contudo, ressalta Hely Lopes Meirelles (2006, p. 170) essa modalidade de ação não impede a propositura de ações individuais sobre o mesmo objeto e não gera litispendência.

Dessa forma, a ação civil pública é um instrumento hábil a buscar o fornecimento de medicamentos de elevado custo por parte do Estado, assim como é evidente a legitimidade do Ministério Público para compor o pólo ativo da aludida ação.

\section{CONCLUSÃO}

O direito à saúde, e consequentemente aos medicamentos, está consagrado na Constituição Federal, em seu artigo 196, assim como está expresso o dever do Estado, por meio do Poder Executivo, em assegurar tal direito, sendo evidente.

Verifica-se que a Constituição Federal positiva o princípio da igualdade, de modo que a população pode ter acesso ao medicamento de elevado custo indispensável ao tratamento de suas mazelas, sendo vedado ao Estado a criação de mecanismos de segregação de qualquer natureza como critérios para a distribuição desses medicamentos.

A negativa do Estado no fornecimento de fármacos, incluindo aqui os três entes da Federação, constitui ato lesivo ao direito fundamental à vida e à saúde de quem os requer, podendo, então, ser alvo de análise do Poder Judiciário por meio de ações de conhecimento, mandados de segurança e ações civis públicas, conforme a necessidade do autor. 
O fato de o Poder Judiciário reverter qualquer ato administrativo lesivo, bem como determinar uma conduta positiva do Executivo, não interfere na divisão dos poderes políticos instituídos, porque esse poder está no desempenho sua função precípua: a defesa da Constituição Federal e do próprio ordenamento jurídico brasileiro.

Portanto, é de ser revelado o dever do Poder Executivo de garantir os direitos fundamentais à vida e à saúde por meio do fornecimento de medicamentos de elevado custo, de modo a assegurar o acesso de tais medicamentos à população. A negativa desse fornecimento consiste em ato administrativo lesivo, o que caracteriza uma omissão capaz de infringir normas constitucionais, o que pode ser alvo de análise pelo Poder Judiciário, o qual se valerá de todos os meios e remédios legais-constitucionais para fazer cessar tal lesão.

\section{REFERÊNCIAS}

ABRAMOVAY, Pedro. Separação de poderes e medidas provisórias. Rio de Janeiro: Elsevier, 2012.

\section{ARAÚJO, Luiz Alberto David; NUNES JUNIOR, Vidal Serrano. Curso de direito} constitucional. 11. ed. São Paulo: Saraiva, 2007.

BARROSO, Luís Roberto. Da falta de efetividade à judicialização excessiva: direito à saúde, fornecimento gratuito de medicamentos e parâmetros para a atuação judicial. Revista Jurisprudência Mineira, Belo Horizonte, ano 60, n. 188, p. 29-60, jan./mar. 2009.

BRASIL. [Constituição (1988)]. Constituição da República Federativa do Brasil de 1988. Brasília, DF: Presidência da República, 1988. Disponível em: http://www.planalto.gov.br/ ccivil_03/Constituicao/Constituiçao.htm. Acesso em: 10 mar. 2020.

BRASIL. Lei $\mathbf{n}^{\mathbf{0}}$ 8.080, de 19 de setembro de 1990. Dispõe sobre as condições para a promoção, proteção e recuperação da saúde, a organização e o funcionamento dos serviços correspondentes e dá outras providências. Brasília, DF: Presidência da República, 1990. Disponível em: http:// www.planalto.gov.br/ccivil_03/leis/18080.htm. Acesso em: 10 mar. 2020.

BRASIL. Supremo Tribunal Federal. Agravo de Instrumento no 507072. Agravante: Estado de Minas Gerais. Agravado: José Carraro. Relator: Ministro Joaquim Barbosa. Brasília, 30 de maio de 2006. Disponível em: http://www.stf.jus.br/portal/jurisprudencia/listarJurisprudencia. asp? $1=$ medicamentos $\% 20 \mathrm{e} \% 201$ ista $\% 20$ NAO $\% 20$ S.PRES.\&base=baseMonocraticas. Acesso em: 10 mar. 2020.

BRASIL. Supremo Tribunal Federal. Agravo no Recurso Extraordinário no 273.834-4. Segunda Turma. Agravente: Município de Porto Alegre. Agravado: Cristiane Carneiro Bortolaz. Relator: Ministro Celso de Melo. Julgado em: 31 out. 2000. Diário de Justiça Eletrônico, Brasília, 2 fev. 2001.

BRASIL. Supremo Tribunal Federal. Suspensão Segurança $\mathbf{n}^{0}$ 3382. Requerente: Estado rio Grande do Norte. Requerido: Relator do Mandado de Segurança nº 20070046760 do Tribunal de Justiça do Estado do Rio Grande do Norte. Relator: Ministra Presidente Ellen Gracie. Julgado 
em: 22 nov. 2007. Disponível em: http://www.stf.jus.br/portal/jurisprudencia/listarJurisprudencia. asp?s $1=$ medicamentos $\% 20 \mathrm{e} \% 201$ ista $\% 20 \mathrm{E} \% 20$ S.PRES.\&base=basePresidencia. Acesso em: 13 mar. 2020.

BUENO, Cássio Scarpinella. A nova Lei do mandado de segurança. 2. ed. São Paulo: Saraiva, 2010.

CANOTILHO, José Joaquim Gomes. Direito constitucional e teoria da constituição. 7. ed. São Paulo: Almedina, 2008.

CANOTILHO, José Joaquim Gomes; MOREIRA, Vital. Constituição da república portuguesa anotada. 3. ed. Coimbra: Editora Coimbra, 1984.

CARELLI, Rodrigo de Lacerda. Direitos constitucionais sociais e os direitos fundamentais: são os direitos sociais constitucionais direitos fundamentais? Revista de Direito Constitucional e Internacional, São Paulo, v. 11, n. 42, p. 252-257, jan./mar. 2003.

CORRÊA, Márcia Melhomens Sirotheau. Caráter fundamental da inimputabilidade da constituição. Porto Alegre: Sergio Antonio Fabris, 1998.

DALVI, Luciano. Direito constitucional esquematizado. Florianópolis: Conceito, 2008.

GOUVÊA, Marcos Maselli. O direito ao fornecimento estatal de medicamentos. Revista Forense, Rio de Janeiro, v. 370, p. 103-134, 2003.

LEAL, Márcio Flávio Mafra. Ações coletivas: história, teoria e prática. Porto Alegre: Sérgio Antonio Fabris Editor, 1998.

MEIRELLES, Hely Lopes. Mandado de segurança. 29. ed. São Paulo: Malheiros, 2006.

MONTESQUIEU, Charles-Louis de Secondat. O espírito das leis. 2. ed. São Paulo: Martins Fontes, 2000.

ROCHA, Carmem Lúcia Antunes. O princípio da dignidade da pessoa humana e a exclusão social. Revista de Interesse Público, Porto Alegre, n. 4, p. 23-48, out./dez. 1999.

SILVA, José Afonso. Curso de direito constitucional positivo. 25. ed. São Paulo: Malheiros, 2005.

SILVEIRA, Paulo Fernando. O poder judiciário e os direitos individuais (duas poderosas forças antimajoritárias). Revista da Associação dos Juízes Federais do Brasil, Brasília, n. 8, p. 121153, abr./jun. 2007.

TAVARES, André Ramos. Curso de direito constitucional. 5. ed. São Paulo: Saraiva, 2007.

THEODORO JÚNIOR, Humberto. Curso de direito processual civil: teoria geral do direito processual civil e processo de conhecimento. Rio de Janeiro: Forense, 2007.

VIOLANTE, Carlos Alberto M. S. M. Sentença pretendida condenação do estado ao fornecimento de medicamentos, materiais hospitalares e produtos de higiene e limpeza.

Antecipação da tutela. Procedência. Cadernos Jurídicos da Escola Paulista da Magistratura, 
São Paulo, v. 3, n. 8, p. 74-75, mar./abr. 2002.

Como citar: CORRÊA, Daniel Marinho; AMARAL, Ana Cláudia Zuin Mattos do; MARQUESI, Roberto Wagner. A judicialização das questões relativas à recusa do Estado em fornecer medicamentos de alto custo. Scientia Iuris, Londrina, v. 25, n. 1, p. 49-67, mar. 2021. DOI: 10.5433/2178-8189.2021v25n1p49. ISSN: 2178-8189.

Recebido em: 03/08/2020

Aprovado em: 05/03/2021 